\title{
Metábole para Trompete, Trombone, Percussão e Piano (1994) de Mário Ficarelli. Um Comentário Crítico pelo Autor
}

Mário Ficarelli

Este trabalho homenageia o poeta Mário Quintana, de quem há muito sou grande admirador, pela simplicidade, jovialidade e verdadeira poesia no sentido mais amplo que se possa entender quando se pronuncia o seu nome.

Metábole é a designação que os gregos utilizavam para indicar qualquer mudança rítmica ou melódica no decurso de uma composição. Esta composição é inspirada no conjunto da obra de Quintana. E o título dado, mais do que ao seu aspecto musical, refere-se à arte do poeta. Sua obra está eivada de metáboles sem, no entanto, deixar de ser una no pensamento, no conteúdo intrínseco à filosofia plena de graça e leveza, ausente do romantismo vulgar, rica do mais profundo do pensamento humano. Por outro lado, a poesia de Quintana talvez sempre tenha me fascinado pela sua musicalidade. Penso que ele faz literatura como se compusesse música.

A morte de Mário Quintana, ocorrida a 5 de maio, foi coincidente com a encomenda de um trabalho que mal acabara de receber e cuja proposta me oferecia um conjunto de até dez instrumentos ${ }^{1}$. Não tive dúvidas em juntar as coisas. A opção pelos metais e a percussão parecia-me mais heróica para celebrar a passagem do poeta - o piano atuaria como unificador harmônico e principalmen- 
te rítmico-percussivo para criar, por sua vez, o clima propício ao discurso dos demais instrumentos. $\mathrm{O}$ material básico está calcado em uma série, utilizando seus quatro modos, transposições e intercambiamentos.

Não obstante, em virtude da aridez natural resultante da utilização rigorosa do processo serial dodecafônico, são inúmeras as licenças que contrariam a ortodoxia desse processo. Daí as interferências dos recursos do atonal e do tonal. Não acredito absolutamente em fórmulas pré-estabelecidas na criação musical. Se assim fosse, a música seria bloqueada quanto à sua evolução, e a criação, entendida como invenção, estaria fatalmente condenada a meras elucubrações aritméticas ${ }^{2}$. Graças às rupturas com o pré-estabelecido é que, em todos os tempos, a criação ou o invento se processa. Outrossim, não é só no aspecto físico da obra musical que devemos nos ater. Este, o processo físico, é inerente à obra, pois compreende, entre outras coisas, a natureza dos instrumentos, a natureza da construção própria e fundamental para a arte temporal, a natureza acústica segundo os princípios da fisica dos sons (suas combinações e conseqüências) e, por fim, os princípios estéticos relativos ao equilíbrio da obra de arte, anteparo para a consecução dos propósitos do criador, no particular e no geral.

Qual o estado psicológico do criador no momento da criação? Que complexas questões oriundas da reflexão sobre as coisas da vida, fundidas e permeadas pelos problemas quotidianos da existência e da subsistência, pluralizam-se na sua mente quando do ato criativo? O turbilhão de pensamentos da mente acostumada ao exercício diário do pensar é de tal soma, que se torna dificil entender o processo, a não ser pela constatação dos resultado, proezas culturais de centenas e centenas de homens a cada geração, que oferecem ao futuro mais conhecimento e sabedoria. Isso é possível captar pelo grau de sensibilidade espiritual, mas ainda assim... explicar...?

Sempre me é dificil, após cada composição musical concluída, abarcar todo o processo de sua criação e explicar a outros como foi que a realizei. Que se tenha claro que não é o seu aspecto técni- 
co em si, pois que esse é fruto do aprendizado, do exercício, da pesquisa, da experiência somados à correção dos erros. A questão vai muito mais longe quando não nos atemos a fórmulas ou sistemas e tabelas pré-determinados, a fôrmas, a croquis, nos quais deita-se o metal liquefeito para moldar mais um "objeto". É quando se processa a criação musical através da liberação do inconsciente. Como explicar a marcha ou o curso de criação do meu inconsciente? Como explicar conscientemente o que foi produzido pelo inconsciente? Fica-se sempre condenado a permanecer na periferia da questão, do palpável, trazendo à tona ou demonstrando apenas aquilo que qualquer um, com razoáveis conhecimentos técnicos e com um pouco de esforço, pode fazer através de uma partitura. Gostaria imensamente de poder explicar essa outra parte da arte de inventar música: a impalpável. Se alguém dominasse esse conhecimento, poderia explicar a coerência, a força, o gigantesco potencial da mente, que registram para nós uma Missa em si menor, uma Sinfonia Coral, um Crepúsculo dos Deuses ou uma Sagração da Primavera. Como foram feitas essas obras entre tantas e tantas outras? Que mistério encerra esse poder de captar as "correntes de pensamento" que riscam o Universo em todas as direções?" Além do que, como músico apaixonado que sou, acredito que as palavras são pobres para narrar uma música - só a música pode explicar-se por si mesma.

Em minha atuação como professor e pesquisador, já passaram sob meus olhos muitas dezenas de trabalhos, chamados de análise, que procuram explicar como foram construídas determinadas obras musicais. Sempre e sempre circunseritos ao plano técnico. Sem sombra de dúvida (que não me entendam mal os tecnicistas da música), conhecimento e domínio da técnica são condições sine qua non para o desvendar do processo composicional utilizado por determinado compositor em determinada obra; essa, porém, é a primeira parte da questão; diria mesmo o ponto de partida para se abarcar todo o complexo. Contudo, ainda assim o desvendar do mistério de que falei continua por ser resolvido. Existem compositores, em qualquer periodo, que produziram obras que se 
diriam corretas, seja na forma, no uso da linguagem, na aplicação dos recursos instrumentais, em suma, em todos os aspectos técni$\cos$, mas das quais ausente a genialidade.

Nos dias de hoje, graças aos recursos da fonografia, podemos conhecer obras que, de outro modo, jamais teriam saído de escondidos arquivos, pois, no afã de ampliar o leque de ofertas de seus catálogos, muitas gravadoras exumam obras que se costuma apelidar de "fracas". Observe-se que não se trata do simples fato de não serem conhecidas mas, na verdade, por lhes faltar o essencial, que faz com que, na pena de um Beethoven, uma simples escala soe como a mais genial melodia e, na de um Czerny, não passe nunca de um exercício.

Tudo o que escrevi até aqui serve apenas para dizer ao prezado leitor que não espere que, sendo eu mesmo o autor da obra, consiga por isso apresentar mais do que uma mostra de como conectei os recursos técnicos empregados em Metábole, somando-se a intenção de homenagear um de meus ídolos. Desta forma, segue o que denominamos análise.

\section{A série ou material temático:}

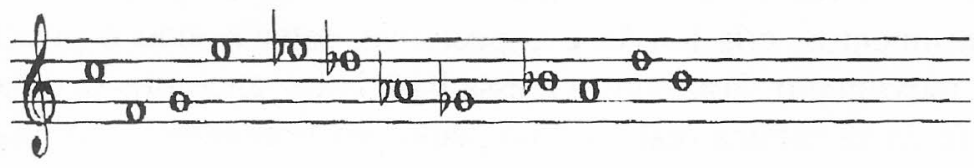

\section{A Estrutura:}

Introdução comp. 1 a 16

Seção A comp. 16 a 60

Seção B comp. 60 a 88

Seção A comp. 89 a 118

Coda comp. 117 a 132 


\section{Introdução}

Os tom-tons anunciam, no 2. ${ }^{\circ}$ compasso, o motivo da morte [. D. . . que será usado na Coda (comp. 119 e seguintes), com ligeira variação:

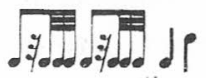

O trompete com surdina reforça uma fanfarra distante do apoiado pelos tom-tons e trombone. No compasso 6, o piano cria uma atmosfera densa, com um efeito polirrítmico:

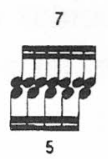

enquanto os metais ativam um desenho, inicialmente com notas longas que vão se comprimindo, provocadas pela percussão até o accelerando, onde trompete e trombone se assenhoreiam do ritmo da percussão no compasso 15, atingindo o início da Seção A (comp. 16).

\section{Seção A}

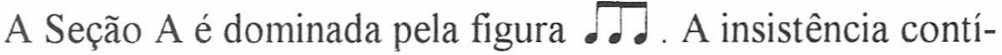
nua desse ritmo no piano, quase como um fundo para os demais instrumentos, cria tensão e expectativa, satisfazendo o princípio do movimento. Sobreposta a essa base linear encontra-se uma interferência rítmica realizada no piano por dobramento de oitavas na mão esquerda, reforçadas pelos bongôs em dinâmica forte e em destaque. A presença do movimento de quartas no trompete e no trombone, de modo incisivo, convocam a um adensamento geral, inclusive com as oitavas duplas no piano, apoio dos tom-tons; todos, em dinâmica fortíssimo, desfecham insistentes acordes concluindo a primeira parte dessa Seção (comps. 35 a 37). A segunda parte toma ainda o intervalo de quarta nos metais, com figuração rápida, superpondo-se à sequêencia rítmica anterior ( . $)$ na região grave do piano. 


\section{Seção B}

Inicia-se no compasso $60 \mathrm{com}$ alteração da unidade de tempo, que passa da subdivisão ternária para a subdivisão binária. $\mathrm{O}$ piano toma o lugar da percussão com marcação rígida de tempo, enquanto o trompete realiza um desenho com portamentos de segunda menor; o trombone atende a essa proposta e ambos convocam o piano para o mesmo desenho em oitavas duplas. Com uma aceleração do tempo, é atingida a segunda parte desta Seção, onde prevalece o ritmo marcial ( $\sqrt{\%}$ ). Os compassos 87 e 88 , que simultaneamente parafraseiam os compassos 60 e 61, servem de conexão com uma reexposição modificada da Seção A, a qual é interrompida bruscamente no compasso 116.

\section{Coda Estrutural}

No compasso 117 tem início esta Coda, com um diálogo entre os metais, quase como recitativo. $\mathrm{O}$ piano se cala e os dois tomtons, independentemente, marcam um ritmo obstinado até o final da obra. Esta Coda poderia ser designada de "A Morte do Poeta". Morte que não é trágica, como ele mesmo a descreve em seu poema XXXV de "A Rua dos Cataventos".

Para que a homenagem fosse completa, construí a obra inspirando-me em trechos de poesias de Quintana. Desse modo, ao misturar o poeta a morte com o nascimento, dizendo: "Minha morte nasceu quando eu nasci.", inicio Metábole, com o anúncio da morte pelos tom-tons, no compasso 3 , e com o anúncio do nascimento pelo trompete em surdina nos compassos 4 e 5. Para a Seção A, o poema "Os Caminhos estão cheios de Tentações".

Os caminhos estão cheios de tentações.

Os nossos pés arrastam-se na areia lública...

Oh! tomemos os barcos das nuvens! 
A Seção B se orienta em "Inscrição para uma Lareira":

A vida é um incêndio: nela dançamos, salamandras mágicas.

Que importa restarem cinzas

se a chama foi bela e alta?

Em meio aos toros que desabam,

cantemos a canção das chamas!

Cantemos a canção da vida,

na própria luz consumida...

A reexposição da Seção A propõe o poema "Aeroporto"

Eu também, eu também hei de estar no

Grande Aeroporto, um dia,

Entre os outros viajantes sem bagagem...

Tu não imaginas como é bom, como é repousante

Não ter bagagem nenhuma!

Porém, no alto-falante,

Serei chamado por outro nome que não o meu...

Um nome conhecido apenas pelos anjos.

Para a Coda, o poema $\mathrm{XXXV}^{7}$ é retrato de Quintana - sua vida, sua obra:

Quando eu morrer...

Eu levarei comigo as madrugadas,

Pôr-de-sóis, algum luar, asas em bando,

Mais o rir das primeiras namoradas... 


\section{NOTAS}

1. Encomenda da Secretaria de Estado da Cultura, através da Universidade Livre de Música.

2. No exercício do magistério há mais de vinte c cinco anos, sempre que as tarefas que proponho envolvem experiencias contrapontísticas com o dodecafonismo rígido, até os estudantes mais desprovidos de criatividade espelham reflexos de genialidade weberniana, bastando os parâmetros sejam oferecidos c haja razoável formação prévia: o mesmo raramente acontece se o modelo, por cxemplo, for haydniano, só para não digredir geograficamente.

3. Pietro UBALDI, As Noures. São Vicente, Ed. Fundapu. 1984.

4. Mário QUINTANA. "O Aprendiz de Feiticciro". 80 anos de Poesia. São Paulo, Globo, 1984.

5.

Gíobo, 1984. . "Nova Antologia Poética" . 80 anos de Poesia. São Paulo,

6.

7.

lo, Globo, 1984. . Preparativos de Viagem. Rio de Janciro, Globo, 1987. . "A Rua dos Cataventos". 80 Anos de Poesia. São Pau-

Márịo Ficarelli é Compositor e Professor do Depto. de Música da ECA-USP. 